\title{
CROSS CULTURAL ONLINE SHOPPING CONSUMER BEHAVIOR: COMPARISON OF CHINA AND TURKEY
}

\author{
Volkan Husnu Gurcan \\ School of Economics and Management, Beihang University (BUAA), P.R.China
}

\begin{abstract}
In this paper we examine online shopping behavior of two developing countries, China and Turkey. Local cultures have strong effects on consumer behavior in online shopping. Thus examining the cultural effects and examining the differences between different cultures are crucial to propose international, competitive and successful marketing strategies and investments. We determined factors to reflect the cultural difference between Turkey and China in terms of attitude towards online shopping. Attitude towards online shopping is examined through online shopping amount and online shopping frequency. We proposed hypotheses based on the proposed factors. Each hypothesis is examined through the results of applied survey. We also conduct group-based factor analysis in order to examine the distribution-based differences between Turkey and China in terms of online shopping behavior of the customers.
\end{abstract}

Keywords: Online shopping behavior, Cultural difference, Turkey, China.

JEL code: M16 M30 M31

\section{Introduction}

Online shopping is growing exponentially and it is a common belief that the growth trend would keep its speed for a long period of time. Thus potential of online shopping did not fully utilized and there are big opportunities in terms of marketing. Especially in developing countries, both internet usage and online shopping are growing far faster than the World average. Despite of the growth rates, online shopping in developing countries is not practiced adequately. In order to invest on online shopping, the factors that affect consumers' online shopping behavior should be investigated and analyzed especially in developing countries. In this research we examine online shopping behavior of two developing countries: China and Turkey. Local cultures have strong effects on consumer behavior in online shopping. Thus examining the cultural effects and examining the differences between different cultures are crucial to propose international, competitive and successful marketing strategies and investments. We determined factors to reflect the cultural difference between Turkey and China. We proposed hypotheses based on the proposed factors. Each hypothesis is examined through the results of applied survey. We also conduct group-based factor analyses in order to examine the distribution-based differences between Turkey and China in terms of online shopping behavior of the customers. 


\section{Research Background}

The Internet completely changed the competition in traditional economic structure. It defines a new medium to access the customers and serves innovative alternatives to traditional services. The Internet has become the new market place with enormous amount of products, services and suppliers. Online shopping is the popular way of purchasing goods or services. Ease of use and accessibility promote online shopping. Online shopping defines a completely new interaction medium and redefines the factors of consumer behavior. There are various factors that influence consumer behavior in online shopping. Consumer characteristics, cultural characteristics, product characteristic, supplier characteristics and medium characteristics could be listed as the main factors. In the following paragraphs, corresponding literature are given about the cultural difference analysis in terms of factors affecting consumer behavior.

Hirst and Ashwin conducted a research to compare online shopping cultures in London and Bangkok. They conducted a qualitative cultural research and found out that inconvenient and strict deliveries and time consuming and uneasy product returning are common problems for both customers in London and Bangkok. They revealed some cultural differences between London and Bangkok. The returning policy is important for both cities however, customers in Bangkok stated much stronger importance scores to it. By examining results and the literature, authors stated that that the retail shopping experience is more important for the customers from the Far East countries. The authors also stated that the customers from London were more satisfied compared to customers from Bangkok. The customers from London strongly agree about convenience and time saving properties of online shopping. On the other hand, the customers from Bangkok have doubts about the convenience of online shopping (Hirst and Ashwin, 2008).

Lim et al. examined the relationship between purchase intention, perceived usefulness and online shopping behavior. The questionnaires are conducted on Malaysian university students aged between 18 and 34. They employed Structural Equation Modelling to test proposed hypothesis. They revealed that purchase intention has the highest positive correlation to online shopping behavior for the selected customer subset. They also stated that the selected customer's purchase intentions strongly affected by the relatives and media. They explained the effect of relatives and media with the culture-bounded characteristics of the Malaysians (Lim et al., 2016).

Mazaheri et al. constructed a model to examine the impacts emotions on perceptions of site properties. They stated that the impact of the emotional factors depends on the cultural properties. For example, dominance is found to be more correlated with effectiveness perception in China compared to Canada. On the other hand, entertainment is found to be more correlated with effectiveness perception in Canada. The correlation between arousal factor and the perceptions of site properties are found to be independent of the culture. The correlation between the entertainment factor and site involvement is found to be higher in 
China. The correlation between the site attitudes and service attitudes is found to be stronger in China. Thus, in order to be successful in Chinese online market, customers' attitudes toward the web site should be enhanced (Mazaheri et. al., 2011).

Pookulangara proposed a conceptual model and using Technology Acceptance Model (Davis et al., 1989). In the research, Perceived ease-of-use (Monsuwé et al., 2004), Perceived usefulness, subjective norms, perceived enjoyment and Cultural characteristics are investigated and corresponding hypothesis are proposed (Pookulangara, 2011).

Yoon conducted a research on analysis of cultural effects on consumer acceptance of online shopping. Yoon stated that uncertainty avoidance and long-term orientation affect reasonably the connection between trust and intention to use. Some of the results stated in the corresponding research are stated in the following sentences. Together with high uncertainty avoidance, correlation between trust and intention to use become weaker. Together with high long-term orientation, correlation between trust and intention to use become stronger. Together with high Masculinity, correlation between perceived usefulness and intention to use become stronger (Yoon, 2009).

Alyami and Spiteri conducted a research to examine online shopping motivations, perceptions and behaviors of the international university students. They stated that perceived risk is not correlated to attitude towards online shopping. However they found that experience is strongly correlated to attitude towards online shopping. They also stated that behavioral intentions and demographics are not strongly correlated to actual behavior. (Alyami and Spiter 2015).

Lissitsa and Kol conducted a research on the internet adoption and online shopping behavior among Generation X and Generation Y. They concluded that the rate of internet access is higher in Generation Y. They also found out that Generation X bought electrical appliances and vacations more than Generation $\mathrm{Y}$ in online platforms. The reason is mentioned to be the higher disposable income, and more free time Generation X has (Lissitsa and Kol, 2016).

Smith et al. conducted a cross-cultural comparison of Norway, Germany, and the United States in terms of effect of the culture on online shopping behavior (Smith et al., 2013).

Clemes et al. proposed a theoretical framework to identify the online shopping factors influencing decisions of Chinese. Perceived risk, consumer income, subjective norms, product spectrum, and online shopping platform-based factors are found to be most effective factors of online shopping behavior (Clemes et al., 2014). 


\section{Hypothesis Definition}

\subsection{Factor Construction}

Various theoretical models are examined to determine factors influencing consumer purchasing pattern. Proposed factors are constructed by examining previous theoretical models for consumer purchasing pattern and common customer types in the online shopping environment. Initial factors are given in Table 1.

Table 1: Initial Factors.

A) Consumer Characteristics

1) Online Shopping and Internet Experience of Customer

2) Demographic Factors

3) Technology Perception of Customer

4) Time and Access Limitations of Customer to Alternatives

5) Interaction Need of Customer

6) Perceived Entertainment

B) Product Characteristics

7) Product Related Factors

C) Supplier Characteristics
8) Trust
9) Safety Perception
10) Customer Oriented Approach

11) Reputation and Marketing Strategies

12) Competitiveness

D) Web Site Characteristics

13) Easiness of Usage

14) Design of the Web site

15) Innovativeness

E) Cultural Characteristics

16) Social Influence

17) Uncertainty avoidance

18) Power distance

19) Masculinity

20) Indulgence

21) Individualism

22) Long-Term Orientation 


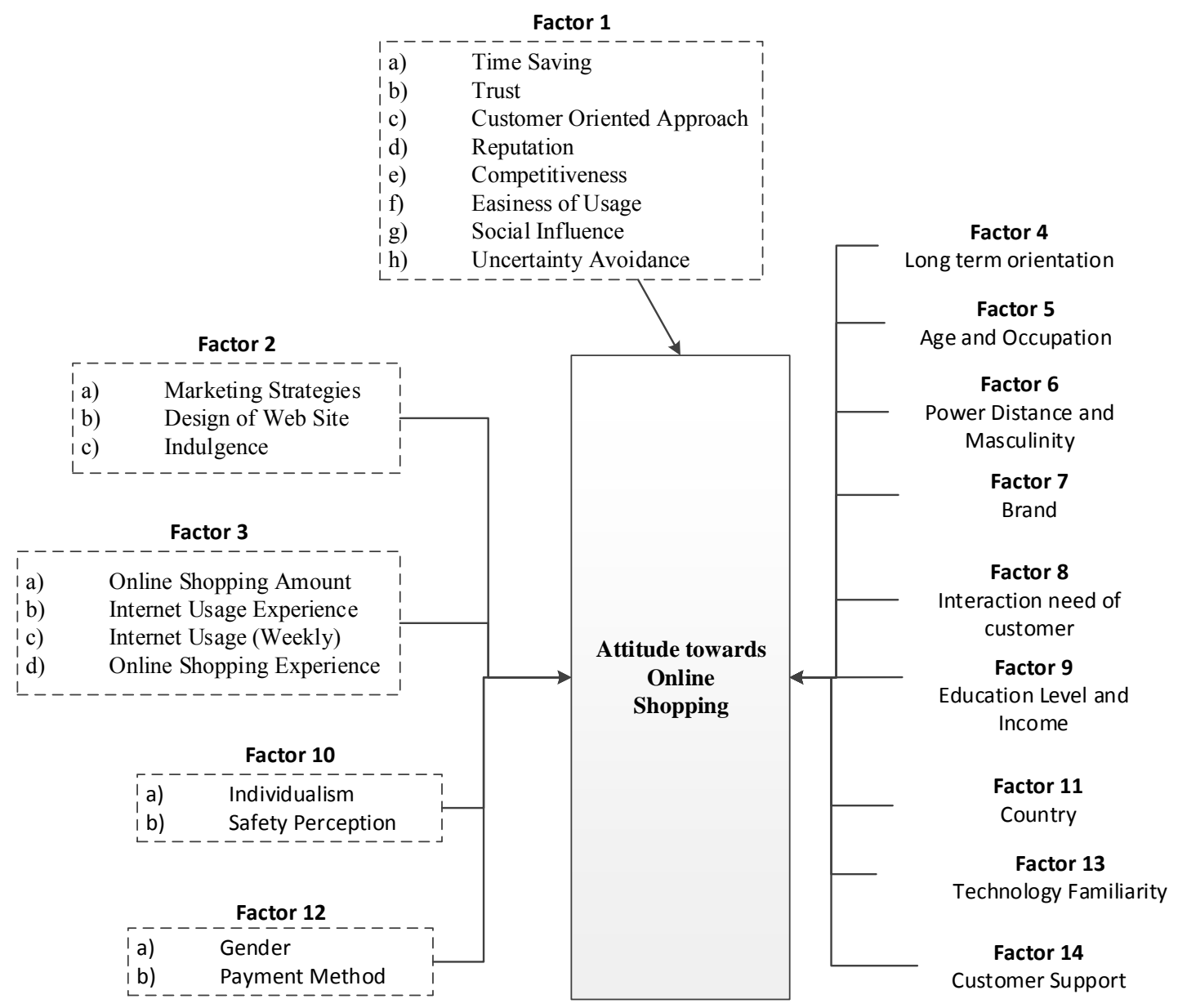

Figure 1: Final Factors and their relations with Attitude towards Online Shopping

After the initial factors are determined given by examining the literature, we analyze each factor through factor and reliability analysis and final factor set is constructed. According to the extracted factors through factor analysis, we revised our model and rearrange the factors and questionnaire accordingly. Total variance calculations indicate the optimum factor count to be 14. The calculations give the initial 48 eigenvalues and 14 eigenvalues after extraction and 14 eigenvalues after rotation. The final set of factors effecting online shopping behavior are given in Figure 1. Final factors and sub-factors are given in Table 2. The main modifications according to the factor analysis results could be listed as follows:

a) Safety Perception and Individualism is reflected as a single factor as a result of factor analysis results. That is result of the characteristics of the corresponding questions in the questionnaire. However factor is separated in to two as a result of the negative average covariance among items.

b) Due to the Negative correlation factor 12 is also split into two such as Gender and Payment Method. 
Table 2: Final Factors.

\begin{tabular}{|c|c|c|c|c|c|}
\hline Main Factor & Label & Detail & $\begin{array}{l}\text { Main } \\
\text { Factor }\end{array}$ & Label & Detail \\
\hline \multirow{8}{*}{ Factor 1} & F1a & Time Saving & Factor 4 & $\mathrm{~F} 4$ & Long term orientation \\
\hline & $\mathrm{F} 1 \mathrm{~b}$ & Trust & \multirow[b]{2}{*}{ Factor 5} & F5a & Age \\
\hline & F1c & $\begin{array}{c}\text { Customer Oriented } \\
\text { Approach }\end{array}$ & & $\mathrm{F} 5 \mathrm{~b}$ & Occupation \\
\hline & F1d & Reputation & \multirow{2}{*}{ Factor 6} & F6a & Power Distance \\
\hline & F1e & Competitiveness & & $\mathrm{F} 6 \mathrm{~b}$ & Masculinity \\
\hline & F1f & Easiness of Usage & Factor 7 & F7 & Brand \\
\hline & F1g & Social Influence & Factor 8 & F8 & Interaction Need Of Customer \\
\hline & F1h & Uncertainty Avoidance & \multirow{2}{*}{ Factor 9} & F9a & Education Level \\
\hline \multirow{3}{*}{ Factor 2} & $\mathrm{~F} 2 \mathrm{a}$ & Marketing Strategies & & $\mathrm{F} 9 \mathrm{~b}$ & Income \\
\hline & $\mathrm{F} 2 \mathrm{~b}$ & Design of Web Site & \multirow{2}{*}{ Factor 10} & F10a & Individualism \\
\hline & $\mathrm{F} 2 \mathrm{c}$ & Indulgence & & F10b & Safety Perception \\
\hline \multirow{4}{*}{ Factor 3} & $\mathrm{~F} 3 \mathrm{a}$ & $\begin{array}{c}\text { Online Shopping } \\
\text { Amount (Last Year) }\end{array}$ & Factor 11 & F11 & Country \\
\hline & $\mathrm{F} 3 \mathrm{~b}$ & $\begin{array}{c}\text { Internet Usage } \\
\text { Experience }\end{array}$ & \multirow[t]{2}{*}{ Factor 12} & F12a & Gender \\
\hline & $\mathrm{F} 3 \mathrm{c}$ & Internet Usage (Weekly) & & $\mathrm{F} 12 \mathrm{~b}$ & Payment Method \\
\hline & $\mathrm{F} 3 \mathrm{~d}$ & $\begin{array}{c}\text { Online Shopping } \\
\text { Frequency }\end{array}$ & Factor 13 & F13 & Technology Familiarity \\
\hline & & & Factor 14 & F14 & Customer Support \\
\hline
\end{tabular}

\subsection{Hypotheses}

All hypotheses are derived from those observations in the literature. Comparison of Turkey and China in terms of cultural characteristics is given in Figure 2 (https://geert-hofstede.com/, 2016). The hypotheses and corresponding factors for each hypothesis are given in Table 3. 


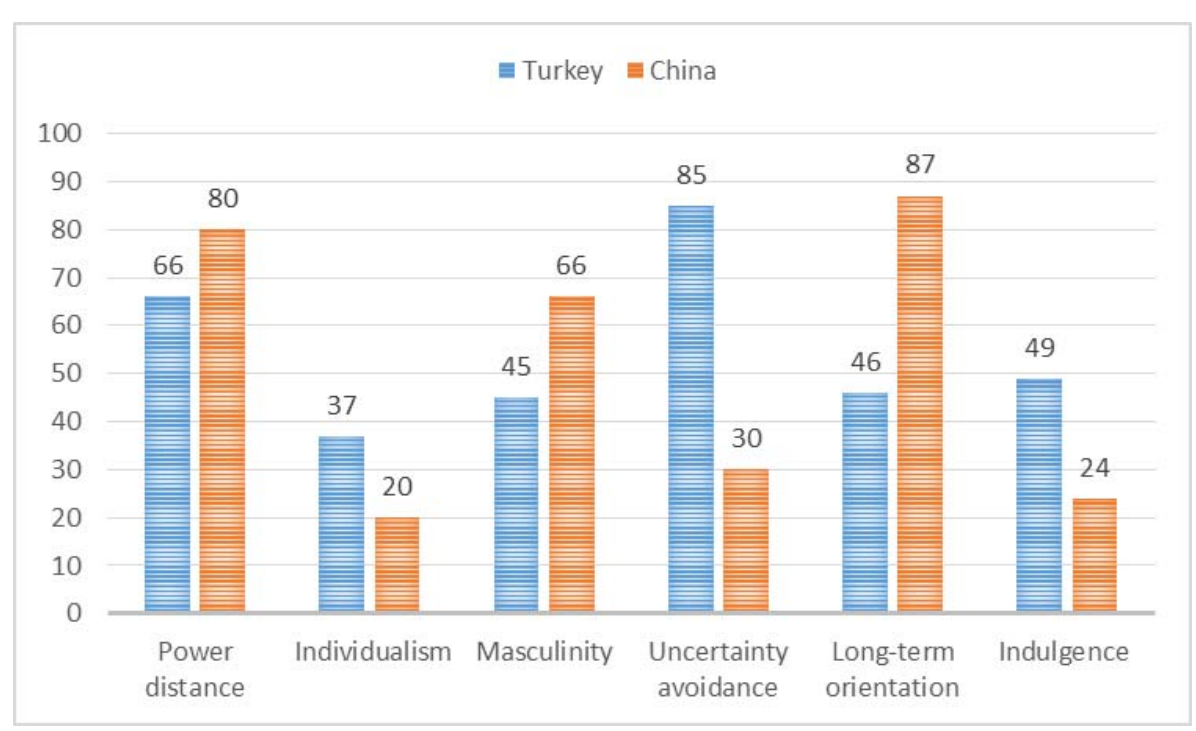

Figure 2: Cultural Characteristics of Turkey and China (https://geert-hofstede.com/, 2016).

Table 3: Defined Hypotheses.

\begin{tabular}{|c|c|c|}
\hline No & Factor & Hypothesis \\
\hline H1 & F8 & $\begin{array}{l}\text { Online shopping customers from Turkey have significantly higher degree of interaction } \\
\text { requirements compared to Online shopping customers from China. }\end{array}$ \\
\hline $\mathrm{H} 2$ & F4 & $\begin{array}{l}\text { Online shopping customers from Turkey have significantly higher degree of Long Term } \\
\text { Orientation compared to Online shopping customers from China. }\end{array}$ \\
\hline $\mathrm{H} 3$ & F1b & Turkish customers are more open to purchasing from unknown web sites. \\
\hline $\mathrm{H} 4$ & F10 & Chinese customers feel safer than Turkish customers especially for new web sites. \\
\hline H5 & F1 & $\begin{array}{l}\text { High Customer Oriented Approach is more positively correlated to attitude of customer } \\
\text { towards online shopping in China. }\end{array}$ \\
\hline H6 & F7 & Brand factor is more effective for Chinese customers in online shopping. \\
\hline $\mathrm{H} 7$ & F1e & $\begin{array}{l}\text { Chinese customers demand higher level of competition compared to Turkish customers in } \\
\text { online shopping. }\end{array}$ \\
\hline $\mathrm{H} 8$ & F1g & Social Influence is more dominant in China in online shopping. \\
\hline H9 & F1h & $\begin{array}{l}\text { Online shopping customers from China are more prone to Social Influence compared to } \\
\text { customers from Turkey. }\end{array}$ \\
\hline $\mathrm{H} 10$ & F6a & $\begin{array}{l}\text { Chinese customers care about status reflection of the web sites more than Turkish } \\
\text { customers. }\end{array}$ \\
\hline H11 & F6b & Chinese customers give precedence to excellence more than Turkish customers do. \\
\hline H12 & $\mathrm{F} 2 \mathrm{c}$ & Turkish customers promote Innovative and web sites more than Chinese customers do. \\
\hline $\mathrm{H} 13$ & F10 & Chinese customers trust harder than Turkish customer to web sites. \\
\hline H14 & $\mathrm{F} 3 \mathrm{~b}$ & $\begin{array}{l}\text { Internet experience impact online shopping frequency of customer towards online shopping } \\
\text { more significantly in China compared to Turkey. }\end{array}$ \\
\hline
\end{tabular}


Hypothesis 1, "H1: Online shopping customers from Turkey have significantly higher degree of interaction requirements compared to Online shopping customers from China", is defined to reveal cultural difference in terms of "Interaction Needs of Customers" factor. The hypothesis is derived from the following observations. In China, shopping malls are closing as a result of the effects of online shopping. However in Turkey, the shopping mall culture is not that old and still popular. The popularity of shopping malls are reflected to the online shopping rates in Turkey. The percentage of population shopping online in Turkey $(1.7 \%)$ is lower than the corresponding percentage $(8.5 \%)$ in China (TÜBİSAD: E-commerce report, 2014, Hong 2016).

Hypothesis 2, "H2: Online shopping customers from Turkey have significantly higher degree of Long Term Orientation compared to Online shopping customers from China" is defined to reveal cultural difference in terms of "Long Term Orientation" factor. The hypothesis is derived from the details given in Figure 1. China has a high long-term orientation score of 87 compared to Turkey's intermediate long-term orientation score of 46 (https://geert-hofstede.com/, 2016). High long-term orientation scores mean pragmatism and future-orientation. This implies the dependence of truth on situation, context and time. Pragmatist people are able to adapt traditions easily to the evolving conditions. Score of long-term orientation is strongly differentiate Western and Asian countries. Long-term oriented societies are characterized commonly found in Asian countries. On the other hand short-term oriented societies are commonly found in Western countries. Chinese customers are known for their lack of loyalty. On the other hand Turkish customers are known for high loyalty under high satisfaction.

Hypothesis 3, "H3: Turkish customers are more open to purchasing from unknown web sites." is defined to reveal cultural difference in terms of customer "Trust" factor. The hypothesis is derived from the details given in Figure 1. It is seen that China has a collectivist culture with low individualism value of 20. Turkey has an individualism score of 37 and it is also collectivistic society. Collectivist cultures are defined to trust harder than individualist cultures. They also tries to eliminate the risk and thus they ate called risk-averse (https://geert-hofstede.com/, 2016).

Hypothesis 4, "H4: Chinese customers feel safer than Turkish customers especially for new web sites." is defined to reveal cultural difference in terms of "Individualism" factor. The hypothesis is derived from the following observations. Attitudes towards personal data sharing are strongly depend on the culture. According to research conducted on attitudes to personal data, Chinese are found to care less about their personal data compared to other countries (Timothy et al., 2014). On the other hand, the high rate and popularity of credit card frauds in media, promote personal data importance among customers in Turkey.

Hypothesis 5, "H5: High Customer Oriented Approach is more positively correlated to attitude of customer towards online shopping in China." is defined to reveal cultural difference in terms of "Customer Oriented Approach factor. The hypothesis is derived from 
the following observation. High customer oriented approach is positively correlated to attitude of customer towards online shopping in both China and Turkey.

Hypothesis 6, "H6: Brand factor is more effective for Chinese customers in online shopping." is defined to reveal cultural difference in terms of brand factor. The hypothesis is derived from the details given in Figure 1. It is seen that Turkey a low masculinity score (45). Turkey is on the Feminine side of the scale. Thus sympathy, consensus, and modesty are promoted properties in the society. China has a higher masculinity score (66). Masculine societies also spend more on luxury products. They demand effective, formal and convenient advertisements (Timothy et al., 2014).

Hypothesis 7, H7 is defined to reveal cultural difference in terms of Competitiveness factor. Competition is the hardest one in China market. There are worldwide players such as Alibaba. Thus Chinese customers is expected to demand higher competition.

Hypothesis 8, H8 is defined for Social Influence factor. The hypothesis is derived from the details given in Figure 1. It is seen that China has a collectivist culture with low individualism value of 20. Turkey has an individualism score of 37 and it is also collectivistic society. In collectivist societies, people care about group interests more than their own interests.

Hypothesis 9, H9 is defined to reveal cultural difference in terms of Uncertainty Avoidance factor. The hypothesis is derived from the details given in Figure 1. It is seen that Turkey marginally higher scores of uncertainty avoidance (85) than the score of China (30). The higher uncertainty avoidance score implies tendency of minimizing uncertainty. In order to minimize anxiety caused by uncertainty, laws, rules, additional information and rituals are developed by the societies (Mattila, 1999). Therefore, Turkish demand clearer and more informative online shopping platforms than Chinese do. Low score of uncertainty avoidance means flexibility of laws and rules in China. It also indicated that Chinese are more comfortable with ambiguity than Turkish (https://geert-hofstede.com/, 2016).

Hypothesis 10, H10 is defined to reveal cultural difference in terms of Power Distance factor. The hypothesis is derived from the details given in Figure 1. It is seen that power distance value is 80 in China and 66 in Turkey. The higher power distance value of China indicates that inequalities amongst people are acceptable for Chinese. In Turkey, the power distance value is still high, thus high level of control exits and information flow is restricted (https://geert-hofstede.com/, 2016). High power distance means importance of status.

Hypothesis 11, H11 is defined to reveal cultural difference in terms of Masculinity factor. The hypothesis is derived from the details given in Figure 1. It is seen that Turkey a low masculinity score (45). Turkey is on the Feminine side of the scale. Thus sympathy, consensus, and modesty are promoted properties in the society. China has a higher masculinity score (66). The masculinity score indicates that Chinese give precedence to success more than family and leisure. Japan has one of the highest masculinity score (95) in the world. Excellence, 
perfection, and competition are the corresponding reflection of that high masculine character in Japan (https://geert-hofstede.com/, 2016).

Hypothesis 12, H12 is defined to reveal cultural difference in terms of Indulgence factor. Indulgence is the degree of control on desires and impulses. Indulgence degree is strongly related to the way people were raised. Weak control is defined as indulgence and relatively strong control is defined as restraint. Low score of indulgence implies tendency of suspicion and pessimism in the corresponding society. The hypothesis is derived from the details given in Figure 1. It is seen that Turkey has an intermediate indulgence score (49), thus indulgence cannot be used as a deterministic factor. China has a low indulgence score (24), and is called as a restrained society. People in restrained societies known to control their desires according to social norms. They also think that indulging themselves is unacceptable (https://geert-hofstede.com/, 2016).

Hypothesis 13, H13 is defined to reveal cultural difference in terms of Individualism factor. The hypothesis is derived from the details given in Figure 1. It is seen that China has a collectivist culture with low individualism value of 20 . Turkey has an individualism score of 37 and it is also collectivistic society. China is completely differs from western countries in terms of individualism levels. Turkey is in the middle between Europe (Individualism score of 89 for United Kingdom) and China in terms of individualism level. Collectivist cultures are defined to trust harder than individualist cultures. They also tries to eliminate the risk and thus they ate called risk-averse (https://geert-hofstede.com/, 2016).

Hypothesis 14, H14 is defined to reveal cultural difference in terms of Internet Usage Experience and Online Shopping Frequency factors. The Internet experience is a crucial item in online shopping behavior. The hypothesis is derived from the details given in Figure 1. It is seen that China has a collectivist culture with low individualism value of 20 . Collectivist cultures are defined to trust harder than individualist cultures. They also tries to eliminate the risk and thus they ate called risk-averse (https://geert-hofstede.com/, 2016). Thus in order to get comfortable with online shopping, customers need more familiarity with online shopping environment. Thus internet experience impact online shopping frequency of customer towards online shopping more significantly in China compared to Turkey.

\section{Research Methodology}

\subsection{Data Collection}

In this research, we examined online shopping customers from Turkey and China. We determined main factors affecting online shopping behavior of the customers examining current literature and online shopping characteristics of these countries. When the factors and corresponding questions are determined, we construct corresponding survey for each country. The proposed survey is applied to 200 online shopping customers from China and 200 online shopping customers from Turkey. We examined each factor individually and also calculated a 
cultural difference score.

\subsection{Measuring}

In order to compare cultures of countries in terms of online shopping behavior, we define a distance measure for calculating the online shopping behavior difference between countries. Proposed cultural distance measure is similar to the cultural distance evaluation proposed by Morosini, Shane and Singh (1998). Equation for calculating cultural distance of country $\mathrm{x}$ to country $\mathrm{y}$ is given in Equation $1 . \mathrm{F}_{\mathrm{i}}(\mathrm{x})$ is the $\mathrm{i}^{\text {th }}$ factor affecting online shopping behavior of country $\mathrm{x}$ and calculated from the responses of the customers participated in the employed questionnaire. Each factor is evaluated by one or more questions, the $F_{i}$ value is calculated from the normalized averages of the responses to the questions of the $i^{\text {th }}$ factor.

$$
\text { Cultural Distance }(\mathrm{x}, \mathrm{y})=\sqrt{\sum_{i=0}^{\text {Factor count }}\left(F_{i}(x)-F_{i}(y)\right)^{2}}
$$

\section{Analysis and Results}

\subsection{Factor Comparisons}

The corresponding average values for final factors are given in Table 4 for Turkey and China cases. Cultural distance between customers from Turkey and customers from China in terms of online shopping behavior are calculated from these values according to the Formula 1 as 5,465453236. From Table 4, it could be seen that the most differentiating factors between China and Turkey is found to be F1a, F3a, F3d, F9b, and F12b. From these results, China and Turkey are found to be strongly differing in terms of online shopping amount and online shopping frequencies. Time saving, income, and payment method are the most differentiating factors between China and Turkey.

Table 4: Factor Comparisons between China and Turkey.

\begin{tabular}{|c|c|c|c|c|c|c|c|}
\hline \multirow{2}{*}{ Factor } & \multicolumn{3}{|c|}{ China } & \multicolumn{3}{|c|}{ Turkey } & \multirow{2}{*}{$\begin{array}{l}\text { Total } \\
\text { Mean }\end{array}$} \\
\hline & Mean & Minimum & Maximum & Mean & Minimum & Maximum & \\
\hline F1a & 2,99 & 1 & 5 & 4,05 & 1 & 5 & 3,52 \\
\hline F1b & 4,4000 & 1 & 5 & 4,5049 & 1 & 5 & 4,45245 \\
\hline F1c & 4,29 & 1 & 5 & 4,57 & 1 & 5 & 4,43 \\
\hline F1d & 4,58 & 1 & 5 & 4,59 & 1 & 5 & 4,585 \\
\hline F1e & 3,9750 & 1 & 5 & 3,9265 & 1 & 5 & 3,95075 \\
\hline F1f & 4,0783 & 1 & 5 & 4,2418 & 1 & 5 & 4,16005 \\
\hline F1g & 4,2800 & 1 & 5 & 4,2794 & 1 & 5 & 4,2797 \\
\hline F1h & 4,31 & 1 & 5 & 4,71 & 1 & 5 & 4,51 \\
\hline
\end{tabular}


Table 4, cont.

\begin{tabular}{|c|c|c|c|c|c|c|c|}
\hline F2a & 3,77 & 1 & 5 & 3,54 & 1 & 5 & 3,655 \\
\hline F2b & 3,8650 & 1 & 5 & 3,8971 & 1 & 5 & 3,88105 \\
\hline F2c & 3,8175 & 1 & 5 & 3,4436 & 1 & 5 & 3,63055 \\
\hline F3a & 7,91 & 1 & 11 & 3,15 & 1 & 11 & 5,53 \\
\hline F3b & 3,99 & 1 & 5 & 4,44 & 1 & 5 & 4,215 \\
\hline F3c & 3,04 & 1 & 4 & 2,96 & 1 & 4 & 3 \\
\hline F3d & 2,66 & 1 & 3 & 1,80 & 1 & 3 & 2,23 \\
\hline F4 & 3,7950 & 1 & 5 & 3,9044 & 1 & 5 & 3,8497 \\
\hline F5a & 2,69 & 1 & 6 & 3,03 & 1 & 6 & 2,86 \\
\hline F5b & 3,38 & 1 & 8 & 3,33 & 1 & 8 & 3,355 \\
\hline F6a & 3,6825 & 1 & 5 & 3,0392 & 1 & 5 & 3,36085 \\
\hline F6b & 3,98 & 1 & 5 & 3,75 & 1 & 5 & 3,865 \\
\hline F7 & 3,4650 & 1 & 5 & 3,9363 & 1 & 5 & 3,70065 \\
\hline F8 & 3,07 & 1 & 5 & 3,62 & 1 & 5 & 3,345 \\
\hline F9a & 3,82 & 1 & 5 & 3,47 & 1 & 5 & 3,645 \\
\hline F9b & 4,60 & 1 & 9 & 3,88 & 1 & 9 & 4,24 \\
\hline F10a & 3,28 & 1 & 5 & 3,35 & 1 & 5 & 3,315 \\
\hline F10b & 2,73 & 1 & 5 & 2,76 & 1 & 5 & 2,745 \\
\hline F12a & 1,55 & 1 & 2 & 1,49 & 1 & 2 & 1,52 \\
\hline F12b & 3,30 & 1 & 4 & 1,97 & 1 & 5 & 2,635 \\
\hline F13 & 3,18 & 1 & 5 & 3,66 & 1 & 5 & 3,42 \\
\hline F14 & 3,52 & 1 & 5 & 3,43 & 1 & 5 & 3,475 \\
\hline Total Av. & 3,719404 & & & 3,480671 & & & \\
\hline & & & & & & & \\
\hline
\end{tabular}

\subsection{Correlation Analysis}

In order to analyze proposed hypothesis we conduct one-way ANOVA and correlation analysis and analyze corresponding mean of differences, significance values. The corresponding correlation analysis results are given in Table 5 and Table 6 for China and Turkey cases separately.

Table 5: Correlations between Factors China.

\begin{tabular}{|c|c|c|c|c|c|c|c|c|c|c|c|c|c|}
\hline & F1a & F1c & F1e & F1g & F1h & F2c & F3b & F4 & F6a & F6b & F7 & F8 & F10a \\
\hline F1a & 1 & & & & & & & & & & & & \\
\hline F1c &, $22^{* *}$ & 1 & & & & & & & & & & & \\
\hline F1e &, $20^{* *}$ &, $33^{* *}$ & 1 & & & & & & & & & & \\
\hline F1g &, $17^{*}$ &, $47^{* *}$ &, $37^{* *}$ & 1 & & & & & & & & & \\
\hline F1h &, 13 &, $54^{* *}$ &, $36^{* *}$ &, $54^{* *}$ & 1 & & & & & & & & \\
\hline
\end{tabular}


Table 5, cont.

\begin{tabular}{|c|c|c|c|c|c|c|c|c|c|c|c|c|c|}
\hline $\mathrm{F} 2 \mathrm{c}$ &, $15^{*}$ &, $34^{* *}$ &, $53^{* *}$ &, $48^{* *}$ &, $50^{* *}$ & 1 & & & & & & & \\
\hline F3b & ,08 &, $19^{* *}$ &,- 03 &, $29 * *$ &, $21 * *$ & ,01 & 1 & & & & & & \\
\hline F4 &, $21 * *$ &, $30 * *$ &, $39 * *$ &, $38 * *$ &, $41 * *$ &, $44^{* *}$ & ,10 & 1 & & & & & \\
\hline F6a &, $16^{*}$ & ,12 &, $19 * *$ &,- 01 & ,12 &, $48^{* *}$ &,- 11 &, $28 * *$ & 1 & & & & \\
\hline F6b &, $23 * *$ &, $22 * *$ &, $37 * *$ &, $31 * *$ &, $36 * *$ &, $44^{* *}$ & ,06 &, $51^{* *}$ &, $35^{* *}$ & 1 & & & \\
\hline F7 &, $21 * *$ &, $51^{* *}$ &, $48 * *$ &, $49 * *$ &, $50 * *$ &, $36^{* *}$ &, 11 &, $44^{* *}$ &, $26^{* *}$ &, $39 * *$ & 1 & & \\
\hline F8 &, $17 *$ &, $25^{* *}$ &, $36 * *$ &, $42 * *$ &, $29 * *$ &, $33^{* *}$ &, 11 &, $35^{* *}$ &, $14 *$ &, $25 * *$ &, $46 * *$ & 1 & \\
\hline F10a &,- 01 &, 04 &,- 08 &,- 04 &, $17 *$ &, $18^{* *}$ &, 01 &, 13 &, $20 * *$ &, 08 &, 03 &, 01 & 1 \\
\hline $\begin{array}{l}\text { Shopping } \\
\text { Amount }\end{array}$ & ,06 &, $18^{* *}$ &, $16^{*}$ &, $27 * *$ &, $17^{*}$ &, 05 &, $25^{* *}$ & ,09 &,$- 18^{* *}$ & ,06 &, $15^{*}$ &, $14^{*}$ &,$- 15^{*}$ \\
\hline $\begin{array}{l}\text { Shopping } \\
\text { Frequency }\end{array}$ &, $15^{*}$ &, $22 * *$ &, $13^{*}$ &, $32 * *$ &, $19 * *$ &, 12 &, $28 * *$ &,- 10 &, 01 &,- 06 &, 08 &, 10 &,- 05 \\
\hline
\end{tabular}

Table 6: Correlations between Factors Turkey.

\begin{tabular}{|c|c|c|c|c|c|c|c|c|c|c|c|c|c|}
\hline & F1a & F1c & F1e & F1g & F1h & F2c & F3b & F4 & F6a & F6b & F7 & F8 & F10a \\
\hline F1a & 1 & & & & & & & & & & & & \\
\hline F1c &, $22^{* *}$ & 1 & & & & & & & & & & & \\
\hline F1e &, $20^{* *}$ &, $33^{* *}$ & 1 & & & & & & & & & & \\
\hline F1g &, $17^{*}$ &, $47^{* *}$ &, $37^{* *}$ & 1 & & & & & & & & & \\
\hline F1h &, 13 &, $54^{* *}$ &, $36^{* *}$ &, $54^{* *}$ & 1 & & & & & & & & \\
\hline F2c &, 02 &, 06 &, $17^{*}$ &, 10 &, 12 & 1 & & & & & & & \\
\hline F3b &, $15^{*}$ &, $22^{* *}$ &, $13^{*}$ &, $32^{* *}$ &, $19^{* *}$ &,- 09 & 1 & & & & & & \\
\hline F4 &, $21^{* *}$ &, $30^{* *}$ &, $39^{* *}$ &, $38^{* *}$ &, $41^{* *}$ &, $33^{* *}$ &, 10 & 1 & & & & & \\
\hline F6a &, $16^{*}$ &, 12 &, $19^{* *}$ &,- 01 &, 12 &, $40^{* *}$ &,- 11 &, $28^{* *}$ & 1 & & & & \\
\hline F6b &, $23^{* *}$ &, $22^{* *}$ &, $37^{* *}$ &, $31^{* *}$ &, $36^{* *}$ &, $28^{* *}$ &, 06 &, $51^{* *}$ &, $35^{* *}$ & 1 & & & \\
\hline F7 &, $21^{* *}$ &, $51^{* *}$ &, $48^{* *}$ &, $49^{* *}$ &, $50^{* *}$ &, $24^{* *}$ &, 11 &, $44^{* *}$ &, $26^{* *}$ &, $39^{* *}$ & 1 & & \\
\hline F8 &, $17^{*}$ &, $25^{* *}$ &, $36^{* *}$ &, $42^{* *}$ &, $29^{* *}$ &, $29^{* *}$ &, 11 &, $35^{* *}$ &, $14^{*}$ &, $25^{* *}$ &, $46^{* *}$ & 1 & \\
\hline F10a &,- 00 &, 04 &,- 08 &,- 04 &, $17^{*}$ &, $14^{*}$ &, 01 &, 13 &, $20^{* *}$ &, 08 &, 03 &, 005 & 1 \\
\hline $\begin{array}{c}\text { Shopping } \\
\text { Amount }\end{array}$ &, 08 &, $19^{* *}$ &,- 03 &, $29^{* *}$ &, $21^{* *}$ &,- 03 &, $25^{* *}$ &, 09 &,$- 18^{* *}$ &, 06 &, $15^{*}$ &, $14^{*}$ &,$- 15^{*}$ \\
\hline $\begin{array}{c}\text { Shopping } \\
\text { Frequency }\end{array}$ &, 04 &, $15^{*}$ &, $16^{*}$ &, $18^{* *}$ &, $20^{* *}$ &,- 11 &, $28^{* *}$ &, 09 &,- 10 &, 07 &, $17^{*}$ &, $23^{* *}$ &,$- 14^{*}$ \\
\hline
\end{tabular}

The proposed hypothesis $\mathrm{H} 1$ is verified by examining the mean difference of interaction need value and significance of the difference. Mean difference of interaction needs of customers of Turkey, from interaction needs of customers of China is found to be 0,39899 which indicates 0, 39899 differentiation in the average. Thus, Turkish customers have higher degree (0, 39899 higher in the average) of interaction requirements than online shopping customers from China. 
On the other hand, from the ANOVA analysis, it is seen that the mean difference is also statistically significant. The significance value is $0,047<0,05$ and that means there is a meaningful difference between responds from China and Turkey in terms of interaction need of customers.

The proposed hypothesis $\mathrm{H} 2$ is verified by examining the mean difference of long term orientation degree between customers from China and customers from Turkey and significance of the difference. Mean difference of long term orientation degree of customers of Turkey from long term orientation degree of customers of China is found to be 0,552 which indicates significant differentiation. It also indicates that online shopping customers from Turkey are more long term orientated to online shopping platforms $(0,552$ higher in the average) than online shopping customers from China. From the ANOVA analysis, it is seen that the difference is also statistically significant. The significance value is $0,000<0,05$ and that means there is a meaningful difference between responds from China and responds from Turkey in terms of Long Term Orientation degree of Customers.

The proposed hypothesis $\mathrm{H} 3$ is refused by examining the mean difference of trust degree between customers from China and customers from Turkey and significance of the difference. Mean difference of trust degree of customers of Turkey from trust of customers of China is found to be 0,18182 which indicates 0,18182 differentiation in the average. Thus, it indicates Turkish customers have higher degree $(0,18182$ higher in the average) of trust than online shopping customers from China. The difference value is parallel with the proposed hypothesis however the significance of the results should also be checked. On the other hand, from the ANOVA analysis, it is seen that the difference is not statistically significant.

Thus hypothesis is not verified. The significance value is $0,149>0,05$ and that means there is not a meaningful difference between responds from China and Turkey in terms of trust to online shopping.

The proposed hypothesis $\mathrm{H} 4$ is verified by examining the mean difference of safety perception between customers from China and customers from Turkey and significance of the difference. Mean difference of Safety Perception of customers of Turkey from Safety Perception of customers of China is found to be 0,2676. It indicates that online shopping customers from Turkey have higher degree of Safety Perception (0, 2676 higher in the average) than online shopping customers from China. From the ANOVA analysis, it is seen that the difference is also statistically significant. The significance value is $0,000<0,05$ in and that means there is a meaningful difference between responds from China and responds from Turkey in terms of Safety Perception.

The proposed hypothesis $\mathrm{H} 5$ is verified by examining the mean difference of effect of customer orientation between customers from China and customers from Turkey and significance of the difference. Mean difference of the degree of importance of customer orientation for customers from Turkey and China is found to be $-0,2929$. It indicates that online shopping customers from Turkey give less importance to customer orientation (0, 2929 
lower in the average) than online shopping customers from China. Thus high Customer Oriented Approach is more positively correlated to attitude of customer towards online shopping in China. From the ANOVA analysis, it is seen that the difference is also statistically significant. The significance value is $0,007<0,05$ and that means there is a meaningful difference between responds from China and responds from Turkey in terms of importance of Customer Oriented Approach.

The proposed hypothesis H6 is refused by examining the mean difference of brand effect between customers from China and customers from Turkey and significance of the difference. Mean difference of trust of customers of Turkey, from trust of customers of China is found to be 0,1212 which indicates 0,1212 differentiation in the average. Thus, it indicates Turkish customers have higher degree $(0,1212$ higher in the average) of caring brand factor than online shopping customers from China. The difference value is not parallel with the proposed hypothesis. On the other hand, From the ANOVA analysis, it is seen that the difference is not statistically significant. The significance value is $0,802>0,05$ and that means there is not a meaningful difference between responds from China and Turkey in terms of trust to online shopping.

The proposed hypothesis $\mathrm{H} 7$ is refused by examining the mean difference of competitiveness effect between customers from China and customers from Turkey and significance of the difference. Mean difference of competitiveness of customers of Turkey, competiveness demand of customers of China is found to be 0,03535 which indicates 0,03535 differentiation in the average. Thus, it indicates Turkish customers have higher degree $(0$, 03535 higher in the average) of competitiveness demand compared to online shopping customers from China. The difference value is not parallel with the proposed hypothesis. On the other hand, from the ANOVA analysis, it is seen that the difference is not statistically significant. The significance value is $0,446>0,05$ and that means there is not a meaningful difference between responds from China and Turkey in terms of Competitiveness demand.

The proposed hypothesis $\mathrm{H} 8$ is verified by examining the mean difference of social influence degree between customers from China and customers from Turkey and significance of the difference. Mean difference of the degree of Social Influence for customers from Turkey and China is found to be $-0,5454$ which indicates significant differentiation. It also indicates that online shopping customers from Turkey is less prone to Social Influence (0,5454 lower in the average) than online shopping customers from China. Thus Social Influence is more positively correlated to attitude of customer towards online shopping in China as the hypothesis indicates. From the ANOVA analysis, it is seen that the difference is also statistically significant. The significance value is $0,006<0,05$ and that means there is a meaningful difference between responds from China and responds from Turkey in terms of Social Influence.

The proposed hypothesis H9 is refused by examining the mean difference of uncertainty avoidance degree between customers from China and customers from Turkey and significance 
of the difference. Mean difference of the degree of Uncertainty Avoidance for customers from Turkey and China is found to be $-0,3080$. It indicates that online shopping customers from China demand more informative web sites than customers from Turkey $(0,3080$ lower in the average). Thus Uncertainty Avoidance is more positively correlated to attitude of customer towards online shopping in Turkey. This result contradicts with the proposed hypothesis. From the ANOVA analysis, it is seen that the difference is statistically significant. The significance value is $0,002<0,05$ and that means there is a meaningful difference between responds from China and responds from Turkey in terms of Uncertainty Avoidance.

The proposed hypothesis H10 is verified by examining the mean difference of power distance degree between customers from China and customers from Turkey and significance of the difference. Mean difference of the degree of Power Distance for customers from Turkey and China is found to be 0,5909 which indicates significant differentiation. It also indicates that online shopping customers from Turkey is more prone to Power Distance (0, 5909 higher in the average) than online shopping customers from China. Thus Power Distance is more positively correlated to attitude of customer towards online shopping in China as the hypothesis indicates. From the ANOVA analysis, it is seen that the difference is also statistically significant. The significance value is $0,002<0,05$ and that means there is a meaningful difference between responds from China and responds from Turkey in terms of Power Distance.

The proposed hypothesis H11 is refused by examining the mean difference of masculinity degree between customers from China and customers from Turkey and significance of the difference. Mean difference of trust of customers of Turkey, Masculinity demand of customers of China is found to be 0,0330 which indicates 0,0330 differentiation in the average. Thus, it indicates Turkish customers have higher degree $(0,0330$ higher in the average) of Masculinity demand compared to online shopping customers from China. The difference value is not parallel with the proposed hypothesis. From the survey results it could be inferred that Turkish customers give more precedence to excellence more than Chinese customers do. On the other hand, from the ANOVA analysis, it is seen that the difference is not statistically significant. The significance value is $0,736>0,05$ and that means there is not a meaningful difference between responds from China and Turkey in terms of Masculinity demand.

The proposed hypothesis $\mathrm{H} 12$ is refused by examining the mean difference of indulgence degree between customers from China and customers from Turkey and significance of the difference. Mean difference of trust of customers of Turkey, Indulgence of customers of China is found to be 0,1767 which indicates 0,1767 differentiation in the average. Thus, it indicates Turkish customers have higher degree ( 0,1767 higher in the average) of Indulgence compared to online shopping customers from China. China has a low indulgence score, and is called as a restrained society thus it confirms hypothesis. However the significance is not as much as expected. On the other hand, From the ANOVA analysis, it is seen that the difference is not statistically significant. The significance value is $0,547>0,05$ and that means there is not a meaningful difference between responds from China and Turkey in terms of Indulgence. 
The proposed hypothesis H13 is verified by examining the mean difference of individualism degree between customers from China and customers from Turkey and significance of the difference. Mean difference of individualism of customers of Turkey from China is found to be $-0,2878$. It also indicates that online shopping customers from Turkey have lower individualism value $(0,2878$ lower in the average) than online shopping customers from China. Thus customers from Turkey feel less safe and they are less open to new web sites. From the ANOVA analysis, it is seen that the difference is also statistically significant. The significance value is $0,013<0,05$ and that means there is a meaningful difference between responds from China and responds from Turkey in terms of individualism of Customers.

Hypothesis 14 is verified with the correlation calculations between Internet Usage Experience and Online Shopping Frequency (Last Year). From the correlation calculations, it is seen that Internet experience impact attitude of customer towards online shopping more significantly in China $(0,347)$ compared to Turkey $(0,283)$.

Type of the items bought from online also depend on many factors. In Table 7 and Table 8 results of the performed correlation analysis between Items Bought and the following factors: gender, age, occupation, education level and income. The following collusions are derived from the correlation analysis:

Table 7: Correlation Analysis for Gender, Age and Occupation and Items Bought.

\begin{tabular}{|c|c|c|c|c|c|c|c|c|c|}
\hline \multirow[b]{2}{*}{404 Items } & \multicolumn{3}{|c|}{ Gender } & \multicolumn{3}{|c|}{ Age } & \multicolumn{3}{|c|}{ Occupation } \\
\hline & C\&T & China & Turkey & C\&T & China & Turkey & C\&T & China & Turkey \\
\hline Apparel &, $27^{* *}$ &, $18^{* *}$ &, $33^{* *}$ &,$- 13^{* *}$ &,- 13 &,- 09 & 03 &,- 04 & ,09 \\
\hline Cosmetics &, $29^{* *}$ &, $38^{* *}$ &, $19^{* *}$ &,- 07 &,$- 18^{*}$ & ,02 &,- 03 &,- 07 & 0 \\
\hline Daily necessities &, $15^{* *}$ &, $29^{* *}$ &,- 10 &,- 08 &,- 03 & ,08 & ,02 & ,02 & 0 \\
\hline Food &, 05 &, $16^{*}$ &,- 13 &,- 07 &,- 08 & ,04 &,- 03 &,- 08 & 0 \\
\hline $\begin{array}{l}\text { House Hold } \\
\text { Goods }\end{array}$ &,- 06 &,- 12 &,- 08 &,- 05 &,- 05 &, 11 & ,02 &, 01 & ,02 \\
\hline Computers &,$- 33^{* *}$ &,$- 22^{* *}$ &,$- 43^{* *}$ &, 01 &,- 08 &,- 02 &,- 08 &,- 05 &,- 10 \\
\hline $\begin{array}{l}\text { Cell Phones and } \\
\text { Accessories }\end{array}$ &,$- 13^{* *}$ &,- 08 &,$- 24^{* *}$ &,$- 11^{*}$ &,$- 15^{*}$ & ,04 &,$- 10^{*}$ &,$- 15^{*}$ &,- 08 \\
\hline $\begin{array}{c}\text { Cameras \& } \\
\text { Photo accessories }\end{array}$ &,$- 11^{*}$ &,- 05 &,$- 23^{* *}$ & 0 &,- 01 & ,06 &,- 04 &,- 06 &,- 02 \\
\hline Tickets &,- 07 &, 11 &,$- 23^{* *}$ & ,09 & ,07 & ,07 &,- 04 &,- 12 &, 01 \\
\hline Sporting Goods &,$- 13^{* *}$ &,$- 18^{*}$ &,- 10 &,- 03 &, 05 &,- 08 &,- 01 & ,06 &,- 10 \\
\hline Books &, 07 & ,06 & ,07 & ,06 &,- 01 &, $15^{*}$ & ,06 &, 06 &, 07 \\
\hline
\end{tabular}

- Online apparel, cosmetic and computer purchases strongly depend on the gender factor in both China and Turkey. 
- Online daily necessities, food and sporting good purchases strongly depend on the gender factor in China. However gender factor is not deterministic for online daily necessities and food purchases in Turkey.

- Online Cell Phones and Accessories, Tickets and Cameras \& Photo accessories purchases strongly depend on the gender factor in Turkey. However gender factor is not deterministic for online daily necessities and food purchases in China.

- Online cosmetic purchase strongly depend on the age factor only in China.

- Occupation factor has similar effects on the type of items bought online in China and Turkey.

- Online apparel, cosmetic and book purchases strongly depend on the education level factor only in Turkey.

- Online computer purchases strongly depend on the education level factor only in China.

- Online apparel and house hold good purchases strongly depend on the income factor only in China.

- Online food, cosmetic and ticket purchases strongly depend on the income factor only in Turkey.

Table 8: Correlation Analysis for Education Level and Income and Items Bought.

\begin{tabular}{|c|r|r|r|r|r|r|}
\hline & \multicolumn{2}{|c|}{ Education Level } & \multicolumn{3}{c|}{ Income } \\
\hline 404 Items & \multicolumn{1}{|c|}{ C\&T } & China & Turkey & C\&T & China & Turkey \\
\hline Apparel &,$- 10^{*}$ &,- 11 &,$- 15^{*}$ &,$- 10^{*}$ &,$- 14^{*}$ &,- 12 \\
\hline Cosmetics &, $13^{* *}$ &, 05 &, $17^{*}$ &, 05 &,- 08 &, $17^{*}$ \\
\hline Daily necessities &, $10^{*}$ &, 02 &,- 02 &, $13^{* *}$ &, 02 &, 11 \\
\hline Food &, 09 &, 02 &, 03 &, $12^{* *}$ &, 01 &, $17^{*}$ \\
\hline House Hold Goods &, $12^{*}$ &, 07 &, 05 &, $18^{* *}$ &, $19^{* *}$ &, 03 \\
\hline Computers &, $12^{*}$ &, $16^{*}$ &, 11 &, $18^{* *}$ &, $17^{*}$ &, $21^{* *}$ \\
\hline Cell Phones and Accessories &, 03 &,- 02 &,- 02 &, $10^{*}$ &, 10 &, 01 \\
\hline Cameras \& Photo accessories &,- 01 &, 03 &,- 09 &, 01 &, 00 &,- 03 \\
\hline Tickets &, 04 &, 02 &, 09 &, $12^{*}$ &, 13 &, $17^{*}$ \\
\hline Sporting Goods &, 03 & 0 &, 02 &, 05 &, 11 &,- 07 \\
\hline Books &, $14^{* *}$ &, 09 &, $16^{*}$ &, 08 &, 04 &, 09 \\
\hline
\end{tabular}

\subsection{Group-based Analysis}

Turkey and China differ in terms of both Online Shopping Amount and Shopping Frequency. From Table 9, it is seen that online shopping customers from China makes online shopping more frequently compared to online shopping customers from Turkey. The amount spend by online shopping customers from China is also higher compared to the amount spend by online shopping customers from Turkey. 
Table 9: Means for Online Shopping Amount and Shopping Frequency (Dependent Variables).

\begin{tabular}{|c|c|c|c|c|c|}
\hline & & \multicolumn{2}{|c|}{ Online Shopping Amount } & \multicolumn{2}{|c|}{ Shopping Frequency } \\
\hline & & China & Turkey & China & Turkey \\
\hline \multirow{3}{*}{ Total } & Mean & 7,91 & 3,15 & 2,65 & 1,80 \\
\hline & $\mathrm{N}$ & 200 & 204 & 200 & 204 \\
\hline & Std. Deviation & 3,486 & 2,678 & 632 &, 750 \\
\hline
\end{tabular}

\subsubsection{Age}

From Multiple Comparisons for Shopping Frequency and Amount (Dependent Variables) and Education level, it is seen that online shopping amount depends on the age of the online shopping customer in China. However there is not any significant difference between the age groups under 50. The significant difference in online shopping amount is between age groups under 50 and over 50. People under 50 spend more on online shopping compared to people over 50 in China. On the other hand, there is a correlation between online shopping frequency and the age of the online shopping customers in China. It is also seen that, there is an obvious correlation between online shopping amount significantly and the age of the online shopping customer in Turkey. On the other hand, there is not any correlation between online shopping frequency and the age of the online shopping customers in Turkey.

Table 10: Multiple Comparisons for Shopping Frequency (Dependent Variable) and Age.

\begin{tabular}{|c|c|c|c|c|c|c|c|}
\hline \multirow{3}{*}{ (I) Age } & \multirow{2}{*}{$(\mathrm{J})$ Age } & $\begin{array}{c}\text { Mean } \\
\text { Difference }\end{array}$ & $\begin{array}{c}\text { Std. } \\
\text { Error }\end{array}$ & Sig. & $\begin{array}{c}\text { Mean } \\
\text { Difference }\end{array}$ & Std. Error & \multirow{2}{*}{ Sig. } \\
\cline { 2 - 8 } & $21-30$ &, 250 &, 358 &, 982 & $-1,205$ &, 700 &, 520 \\
\hline \multirow{4}{*}{20 or less } & $31-40$ &, 387 &, 358 &, 888 & $-2,232^{*}$ &, 690 &, 018 \\
\cline { 2 - 8 } & $41-50$ &, 467 &, 386 &, 832 & $-2,424^{*}$ &, 741 &, 016 \\
\cline { 2 - 8 } & $51-60$ & 2,000 &, 557 &, 006 &,- 868 &, 890 &, 925 \\
\cline { 2 - 8 } & More then 60 &, 667 &, 498 &, 763 & $-2,756$ & 1,022 &, 080 \\
\hline
\end{tabular}

From the Table 10, it is seen that online shopping frequency significantly differs between the age level " 20 or less" and the age levels " $31-40$ " and " $41-50$ " in Turkey. On the other hand there is not a significant correlation between online shopping frequencies significantly and the age of the online shopping customer in China.

\subsubsection{Education Level}

From Multiple Comparisons for Shopping Frequency and Amount (Dependent Variables) and Education level, it is seen that online shopping amount depends on the education level of the 
online shopping customer in China. Online shopping amount increases with the increase in education level. However the online shopping customers with less than high school degree spend more on online shopping compared to online shopping customers with high school and college degrees. It is also seen that online shopping amount and online shopping frequency is almost independent of the education level of the online shopping customer in Turkey. From the Table 11, it is seen that online shopping amount significantly differs between the Education Level "Less than High School" and the Education Level "University" in Turkey. On the other hand there is not a significant correlation between online shopping amounts significantly and the education level of the online shopping customer in China.

Table 11: Multiple Comparisons for Online Shopping Amount (Dependent Variable) and Education Level.

\begin{tabular}{|c|c|c|c|c|c|c|c|}
\hline \multirow{2}{*}{ (I) Education Level } & \multirow{2}{*}{$\begin{array}{c}|c| \\
\text { (J) Education Level }\end{array}$} & $\begin{array}{c}\text { Mean } \\
\text { Difference }\end{array}$ & Std. Error & Sig. & $\begin{array}{c}\text { Mean } \\
\text { Difference }\end{array}$ & Std. Error & Sig. \\
\hline \multirow{3}{*}{$\begin{array}{c}\text { Less than High } \\
\text { School }\end{array}$} & High school & 1,250 & 2,075 &, 975 & $-1,673$ &, 837 &, 271 \\
\cline { 2 - 9 } & College &, 535 & 1,771 &, 998 &,- 767 & 1,009 &, 942 \\
\cline { 2 - 9 } & University & $-1,555$ & 1,724 &, 896 & $-2,575^{*}$ &, $803^{*}$ &, 014 \\
\cline { 2 - 9 } & Postgraduate & $-1,257$ & 1,788 &, 956 & $-2,143$ &, 853 &, 092 \\
\hline
\end{tabular}

\subsubsection{Income}

From Multiple Comparisons for Shopping Frequency and Amount (Dependent Variables) and Education level, it is seen that online shopping amount and online shopping frequency correlate with the income of the online shopping customers in China. The online shopping customers having income of 8001-10000 Yuan per month spend more than other customers. On the other hand there is not a direct correlation between the income level and online shopping amount in Turkey. Online shopping frequency correlates with the income level in Turkey.

\section{Discussion and Conclusions}

This study is cultural difference analysis between Turkey and China in terms of online shopping behavior and consumption of the customers. The results are promising for both the researchers and online shopping platforms. The differences should be investigated and marketing strategies should be shaped according to the revealed differences. The proposed framework provides comparison framework between Turkey and China in terms online shopping behavior of the customers. Cultural difference factors of online shopping behavior is formalized through findings of the proposed research. A cultural difference model between Turkey and China for online shopping behavior of the customers is constructed through the determined factors. 
The results indicate that Chinese customers and Turkish customers vary significantly. Turkish customers have significantly higher degree of interaction requirements than online shopping customers from China. Online shopping customers from Turkey are more long term orientated to online shopping platforms than online shopping customers from China. Turkish customers have slightly higher degree of trust than online shopping customers from China.

Online shopping frequencies and amount of the Chinese and Turkish online shopping customers differs. Chinese online shopping customers shop more frequently with larger amounts relative to Turkish consumers. Online shopping customers from Turkey have significantly higher degree of Safety Perception than online shopping customers from China. Turkish consumers prefer paying cash when they receive the item. Online shopping customers from Turkey give significantly less importance to customer orientation than online shopping customers from China. Turkish customers have slightly higher degree of caring brand factor than online shopping customers from China. Turkish customers have slightly higher degree of competitiveness demand compared to online shopping customers from China. Online shopping customers from Turkey is significantly less prone to Social Influence than online shopping customers from China. Thus Social Influence is significantly more positively correlated to attitude of customer towards online shopping in China.

Online shopping customers from China demand significantly more informative web sites than customers from Turkey. Thus Uncertainty Avoidance is significantly more positively correlated to attitude of customer towards online shopping in Turkey. Online shopping customers from Turkey is significantly more prone to Power Distance than online shopping customers from China. Thus Power Distance is significantly more positively correlated to attitude of customer towards online shopping in China as the hypothesis indicates.

Turkish customers have higher degree of Masculinity demand compared to online shopping customers from China. Turkish customers give slightly more precedence to excellence more than Chinese customers do. Turkish customers have slightly higher degree of Indulgence compared to online shopping customers from China. China has a low indulgence score, and is called as a restrained society. Online shopping customers from Turkey have lower individualism value than online shopping customers from China. Thus customers from Turkey feel less safe and they are less open to new web sites. Internet experience impact attitude of customer towards online shopping more significantly in China compared to Turkey.

Through development of the research, the main limitation was the expending the scope of the research. Covering more than two developing countries and covering more of firms would make the proposed research more valuable. The significant variance between China and Turkey indicates possible differences between other countries. Thus a future larger scoped research could be constructed on the findings of the proposed research. 


\section{References}

Alyami, E. and Spiteri, L. (2015) 'International University Students' Online Shopping Behaviour”, World Journal of Social Sciences, vol. 5, no. 3, pp. 227 - 243.

Clemes, M., Gan, C. and Zhang, J. (2014) “An empirical analysis of online shopping adoption in Beijing, China", Journal of Retailing and Consumer Services, vol. 21, no. 3, pp. 364-375.

"Cultural Characteristics of Turkey and China", [Online] Available at: https://geert-hofstede.com/ [Accessed 13 Aug. 2016].

Davis, F., Bagozzi, R. and Warshaw, P. (1989) "User Acceptance of Computer Technology: A Comparison of Two Theoretical Models", Management Science, vol.35, no. 8, pp. 982-1003.

Hirst, A. and Ashwin, M. (2008) "A Cross Cultural Study of Online Shoppers in London and Bangkok”, Journal of Retail Marketing Management Research, vol. 1, no. 2, pp. 30-43.

Hong (2016) One-third of Chinese shopping malls to close in five years: report. [Online] Available at: http://www.ecns.cn/cns-wire/2016/09-07/225631.shtml [Accessed 7 Jun. 2017]

Lim, Y., Osman, A., Salahuddin, S., Romle, A. and Abdullah, S. (2016) "Factors Influencing Online Shopping Behavior: The Mediating Role of Purchase Intention", Procedia Economics and Finance, 35, pp. 401-410.

Lissitsa, S. and Kol, O. (2016) "Generation X vs. Generation Y - A decade of online shopping”, Journal of Retailing and Consumer Services, 31, pp. 304-312.

Mazaheri, E., Richard, M. and Laroche, M. (2011) "Online consumer behavior: Comparing Canadian and Chinese website visitors", Journal of Business Research, vol. 64, no 9, pp.958-965.

Mattila, A. (1999) "The Role of Culture in the Service Evaluation Process", Journal of Service Research, vol. 1, no. 3, pp. 250-261.

Monsuwé, T. P. Y., Dellart, B. G. C. and de Ruyter, K. (2004) "What drives consumers to shop online? A literature review", International Journal of Service Industry Management, vol. 15, no. 1 , pp. 102-121.

Morosini, P., Shane, S. and Singh, H. (1998) "National Cultural Distance and Cross-Border Acquisition Performance", Journal of International Business Studies, vol. 29, no. 1, pp. 137-158.

Pookulangara, S. (2011) “Consumers' Use of Consumer-Generated Media While Shopping: A 
conceptual Outlook Using Technology Acceptance Model3 and Hofstede's Cultural Dimensions." In International Journal of Electronic Commerce Studies, vol.2, no. 1, pp. 57-66.

Smith, R., Deitz, G., Royne, M., Hansen, J., Grünhagen, M. and Witte, C. (2013) "Cross-cultural examination of online shopping behavior: A comparison of Norway, Germany, and the United States", Journal of Business Research, vol. 66, no 3, pp. 328-335.

Timothy Morey T., Forbath T. and Schoop A. (2015) "Customer Data: Designing for Transparency and Trust", Harvard Business Review May 2015 Issue.

TÜBISSAD Bilişim Sanayicileri Derneği. [Online] Tubisad.org.tr. Available at: http://www.tubisad.org.tr/Tr/News/Sayfalar/TUBISAD-E-Ticaret-2014-BB.aspx [Accessed 1 Jul. 2017].

Yoon, C. (2009) "The effects of national culture values on consumer acceptance of e-commerce: Online shoppers in China", Information \& Management, vol. 46. No. 5, pp. 294-301. 